\author{
Cadernos de \\ ESTUDOS LINGUÍSTIICOS - (59.3), Campinas, pp. 499-517 - set./dez. 2017
}

\title{
DESLIZAMENTO FUNCIONAL DE MARCADORES DISCURSIVOS E ENTOAÇÃO EM NARRATIVAS INFANTIS
}

\author{
ESTER MIRIAN SCARPA ${ }^{1}$ \\ (UNICAMP) \\ CLÁUDIA ANDREA ROST SNICHELOTTO² \\ (UFFS) \\ FLAVIANE ROMANI FERNANDES-SVARTMAN ${ }^{3}$ \\ (USP)
}

\begin{abstract}
RESUMO: Este trabalho objetiva estudar a coesão entoacional e o deslocamento funcional do marcador discursivo "então" na fala da criança. Baseia-se em duas hipóteses conexas: (i) as primeiras manifestações de coesão textual nas protonarrativas infantis são de cunho prosódico, notadamente numa fase em que os sujeitos não produzem nem narrativas propriamente ditas, nem marcas formais consideradas na literatura como coesivas; e (ii) no processo de aquisição da linguagem, certos marcadores discursivos têm função diferente daquela usada pelo adulto e deslocam-se funcionalmente. Trata-se do estudo de caso da fala de uma criança, R., cujos dados recobrem a faixa etária de $1 ; 6^{4}$ a 2;6. Fora selecionados trechos da fala da criança em excertos interpretados como narrativa e a entoação foi analisada através do software PRAAT e com base nos pressupostos teóricos da Fonologia Entoacional (PIERREHUMBERT, 1980; BECKMAN; PIERREHUMBERT, 1986; LADD,1996). Os resultados indicam que marcas prosódicas imprimem coesão em sequências de fragmentos enunciativos, significáveis pelo adulto como marcas de narratividade. Tais marcas revelam a emergência de "paratons" (sequência de frases entoacionais coesivas, dando a impressão gestáltica de um todo coeso). Não há uma "gramática narrativa" propriamente, nem conteúdo lexical reconhecível como tal. As marcas prosódicas, que incidem sobre o marcador "então" e sobre uma sequência de fragmentos de enunciados constituídos por frouxos vínculos sintáticos em instâncias narrativas, imprimem efeito de inteireza textual aos fragmentos. Esses resultados condizem com a hipótese de que a prosódia tem um papel textual aquisicional, e que os marcadores discursivos se deslocam funcionalmente nesse processo.
\end{abstract}

Palavras-chave: Então. Narratividade. Aquisição e prosódia. Paratons.

${ }^{1}$ Universidade Estadual de Campinas - São Paulo - Brasil UFFS - Universidade Federal da Fronteira Sul. Chapecó - Santa Catarina - Brasil / ester.scarpa@gmail.com

${ }^{2}$ UFFS - Universidade Federal da Fronteira Sul. Chapecó - Santa Catarina - Brasil / claudiarost@ uffs.edu.br

${ }^{3}$ USP - Universidade de São Paulo. São Paulo - São Paulo - Brasil / flavianesvartman@usp.br . Projeto "Fraseamento prosódico em português: comparações entre as variedades brasileira e africanas" (Processo CNPq 459634/2014-3)

${ }^{4}$ Adota-se, aqui, o padrão de notação das idades das crianças, na área de Aquisição da Linguagem: ano; mês; dias de idade. 
ABSTRACT: This paper aims at investigating intonation cohesion and the functional change of the discourse marker então ("then") in early narratives. It follows two connected hypotheses: (i) early manifestations of textual cohesion are prosodic in character, especially in a phase when children produce neither narratives in their own right, nor cohesive lexical or grammatical markers recognized as such by the literature; and (ii) in the process of language acquisition, some discourse markers have a different function from the ones in the adult speech and undergo functional changes. This is a longitudinal study of the speech of one child, R., whose data span the age-range from $1 ; 6$ to $2 ; 6$. Instances of the child's speech in excerpts interpreted as narratives were selected and the intonation was analysed using the software PRAAT and in the framework of the Intonational Phonology (PIERREHUMBERT, 1980; BECKMAN; PIERREHUMBERT, 1986; LADD, 1996). The results show that intonational frames for narrative made up from sequences of enumerative rising $\mathrm{F}^{0}$ contours followed by a sequence of ending-point falls are clues to the interpretation of narrativity by the adult as attempts at story telling. This is the emergence of "paratones" (sequences of intonational phrases, giving the gestalt effect of a cohesive whole). There is no narrative grammar as such nor a lexical content that can be seen as narrative: no chronological succession or resolution of events, no plot development, no adequate use of past tense, none such features that, according to the literature, constitute narrativity, are found. Nevertheless, a narrative is recognized through intonational macrostructures together with the discourse marker "então".

Keywords: Then. Narrativity. Acquisition and prosody. Paratones.

\section{INTRODUÇÃO}

Em toda manifestação linguística, sobretudo na interação oral, os falantes empregam ítens lexicais ou partículas que têm sido reconhecidos como indispensáveis tanto para a estruturação ou organização do discurso, para o fluxo de tomada de turnos na conversação, ou para expressar o julgamento do falante sobre o conteúdo semântico do que é dito (KOMAR, 2007; PEZATTI, 2001; MARTELOTTA, 1994; RASO, 2014, entre muitos outros). Sob o rótulo de marcadores discursivos, marcadores pragmáticos, partículas discursivas, marcadores conversacionais, entre outras nomeações, têm-se abrigado elementos linguísticos bastante variados com funções, estruturas sintáticas e categorias gramaticais (conjunções, preposições, advérbios, verbos, adjetivos, etc.) que, em seu deslizamento funcional, sofrem alteração em sua configuração gramatical associada a mudanças semântico-pragmáticas, o que se reflete em um continuum multifuncional. Neste trabalho, adotamos a designação marcadores discursivos (MD) - do inglês, "discourse markers" - cunhada primeiramente por Labov e Fanshel (1977) e adotada por boa parte dos pesquisadores do Brasil (por exemplo, RISSO; SILVA; URBANO, 2006) e do exterior (SCHIFFRIN, 1987; 2003). Segundo ainda Risso, Silva e Urbano (2006), o termo "marcadores discursivos" é reconhecidamente mais abrangente que os demais termos por não limitar o fenômeno a um tipo de texto oral, que é a conversação. Em termos gerais, podemse definir os marcadores como "expressões que relacionam segmentos discursivos" (FRASER, 1999, p. 193).

Por outro lado, a prosódia tem sido apontada como tendo uma dupla face na aquisição. Ela é, ao mesmo tempo, a via privilegiada de engajamento do infante no diálogo e um dos primeiros veículos da organização das formas linguísticas, sobretudo através da construção dos sistemas de ritmo e entoação. Os fatos prosódicos são os recursos expressivos ou subsistemas privilegiados da entrada 
na língua pela criança, aqueles que a criança tem à mão numa fase de parcos recursos de cunho léxico-gramatical. A prosódia estabelece, assim, a ponte inicial entre a organização formal da fala e o potencial significativo e discursivo da língua nos primeiros anos de vida. Muito tem sido trabalhado sobre os sistemas de ritmo (acentos primário e secundário aí incluídos) e entoação nas línguas, sobretudo quando se trata de se estabelecerem recortes que limitam o fenômeno prosódico à frase ou sentença. Com relação à prosódia intersentencial ou textual, estudos sobre ritmo e entoação têm lançado mão do conceito de "paratons" para melhor dar conta de contornos melódicos integrados na construção de textos orais (COUPER-KUHLEN, 1998). São eles macroestruturas entoacionais, que resultam na combinação ou sucessão de unidades entoacionais, como veremos abaixo. Por outro lado, a literatura tem mostrado comportamentos prosódicos comuns a certos marcadores discursivos (RASO, 2014) e à coesão narrativa na manifestação da narratividade (SCARPA, 1985). Este trabalho explora como marcas entoacionais se articulam a certos marcadores discursivos para exprimir textos interpretáveis como narrativos na fala infantil. Uma questão correlata é como as marcas prosódicas da fala inicial começam a se estruturar antes que marcas léxico-gramaticais próprias das narrativas sejam produzidas. Partimos de duas hipóteses conexas:

1. As primeiras manifestações de coesão textual nos dados das crianças são de cunho prosódico, numa fase em que os sujeitos não produzem nem narrativas propriamente ditas, nem marcas formais consideradas na literatura como coesivas (hipótese adiantada por Scarpa, 1985, retomada aqui).

2. No processo de aquisição da linguagem, certos marcadores discursivos (MDs) deslocam-se funcionalmente. Neste trabalho, também damos continuidade à indagação sobre características da aquisição dos MD por crianças falantes nativas do português brasileiro. Objetivamos mostrar o deslizamento funcional do marcador "então" na emergência do discurso narrativo (rotinas dialógicas de contar estórias) através do uso de sequências de tons ou contornos coesivos na fala de crianças pequenas, numa fase em que não se encontram em sua fala recursos léxico-gramaticais para expressar a narratividade. Trata-se de um estudo de caso longitudinal da fala de uma criança, R., cujos dados foram colhidos em áudio-gravações semanais, recobrindo a faixa etária de 1;6 a mais ou menos 2;6. As instâncias de narratividade foram selecionadas e a entoação foi analisada através do software livre PRAAT (BOERSMA; WEENINK, 2016) e com base nos pressupostos teóricos da Fonologia Entoacional (PIERREHUMBERT, 1980; BECKMAN; PIERREHUMBERT, 1986; LADD, 1996).

Organizamos este trabalho em quatro seções, além da introdução e das considerações finais. Na sequência, apresentamos breve revisão da literatura sobre a aquisição dos marcadores discursivos em português brasileiro e o deslizamento funcional do marcador discursivo então. As duas seções seguintes são destinadas, respectivamente, ao embasamento teórico e metodológico e à discussão dos dados. Por fim, discutimos a hipótese de que a prosódia tem um papel aquisicional não só no nível da frase, e que os marcadores discursivos se deslocam funcionalmente nesse processo. 


\section{OS MARCADORES DISCURSIVOS E SUA AQUISIÇÃO EM} PORTUGUESS BRASILEIRO

Há uma tendência geral nas línguas de itens, partículas e expressões lexicais perderem seu valor referencial original e assumirem novas funções pragmáticodiscursivas, derivando marcadores discursivos. Por essa razão, nas três últimas décadas, tem crescido o interesse pela investigação dos marcadores, em diversas áreas da linguística e em diferentes línguas (SCHIFFRIN, 2003).

Também, no Brasil, vários trabalhos sobre marcadores têm sido desenvolvidos com amostras do português. Destaque às pesquisas de Risso $(1993 ; 1996 ; 1999)$ e Risso, Silva e Urbano (2006), especialmente pela abordagem textual-interativa assumida, aos trabalhos de Marcuschi (1989), pela ótica da Análise da Conversação, e às investigações de Castilho (1989), Votre, Cezario e Martelotta (2004), Rost (2001, 2002) e Rost Snichelotto (2009), pela perspectiva funcionalista adotada, apenas para citar algumas.

Assim como as línguas e as perspectivas teórico-metodológicas são distintas, também são frequentes os estudos em interface. É natural, portanto, que se encontrem diferentes significados atribuídos aos marcadores discursivos bem como métodos de análise distintos a depender da(s) perspectiva(s) de cada grupo de pesquisadores (FRASER, 1999; SCHIFFRIN, 2003).

No português brasileiro, são pioneiros os estudos de Silva e Macedo (1989) que, adotando critérios funcionais, efetuaram uma análise variacionista de quatro tipos de marcadores: iniciadores (bom, ah, olha), requisitos de apoio discursivo (né? sabe? entendeu?), especificador (assim) e sequenciador (ai). O corpus investigado foi constituído por 64 entrevistas de informantes cariocas da Amostra Censo 1980, ${ }^{5}$ socialmente estratificados em idade, sexo e escolaridade. A hipótese das autoras era de que, quanto menor fosse a faixa etária, maior seria a probabilidade de uso dos marcadores. Essa hipótese foi confirmada para os marcadores aí e assim, mas foi negada para o emprego dos marcadores né?, sabe? entendeu?, bom e olha, que mostraram a mesma probabilidade de uso nas três faixas etárias.

Os trabalhos brasileiros sobre a aquisição de marcadores discursivos na linguagem infantil são ainda bastante raros. A interface entre variação e aquisição foi objeto de investigação de Macedo (1997), que comparou os marcadores empregados por falantes de português em fase de aquisição da língua materna (L1) e em situação de contato linguístico (L2). A autora analisou duas amostras de fala: uma composta por doze crianças cariocas, de 4 a 10 anos, ${ }^{6}$ e outra constituída por doze informantes indígenas do Alto Xingu. ${ }^{7}$ Buscou-se identificar em que

${ }^{5}$ A Amostra Censo 1980 foi constituída com o objetivo de possibilitar o estudo de processos de variação e mudança na variedade carioca. Os falantes selecionados aleatoriamente em diferentes bairros da cidade do Rio de Janeiro estão estratificados em sexo (masculino e feminino), idade (7 a 14, 15 a 25 , 26 a 49 e mais de 50 anos) e escolaridade ( $1^{\circ}$ e $2^{\circ}$ ciclos do ensino fundamental e ensino médio).

${ }^{6}$ Informantes da Amostra Censo no Rio de Janeiro 1980.

${ }^{7}$ A Amostra Emmerich (1984), constituída entre os anos de 1976 e 1978, é representativa de situações de contato linguístico no Parque Indígena do Xingu. Os informantes, que dominavam tanto o português como uma ou mais variedades indígenas, são homens jovens e velhos, que apresentam pouco ou nenhum contato com falantes brancos. 
idade a criança na fase aquisição de marcadores como L1 começava a adquirir fluência discursiva que a levasse a empregar esses itens e que funções discursivointeracionais eram adquiridas mais cedo. Os resultados mostraram que as crianças cariocas, na faixa dos 4 aos 6 anos de idade, em fase de aquisição do português, já empregam alguns marcadores mais básicos, como sequenciadores (ai) e interjeições $(a h, o h, i h)$, apesar de ainda não reconhecer outros de funções mais complexas (né, sabe e viu, assim, bom e olha, quer dizer). Esse resultado pode indicar, segundo a autora, que a criança, por estar em sua fase egocêntrica, não se coloca na posição do outro e não se preocupa ainda com este tipo de atenuação. A partir dos 8 anos, há incremento na diversidade de marcadores e aumento na frequência de uso.

Os usos de $e$ dai e $e$ ai foram investigados em narrativas de uma criança brasileira por Rojo (1996), revelando que a criança não atribui qualquer sentido a essas expressões que não seja da ordem dessa "musicalidade", pois o uso desses itens coincide com a ação de virar a página, que a literatura tem chamado de preenchimento de pausa. Além disso, até 3: 06, os marcadores não assumem a carga semântica de temporalidade.

Outro estudo sobre o uso de marcadores discursivos na fala infantil foi empreendido por Rost (2001). A análise contemplou duas amostras de fala de 16 crianças da faixa de 2 aos 9 anos. Foram levantados 424 ocorrências de 14 diferentes tipos de marcadores discursivos: sequenciadores (aí, daí, depois e $e$ ), requisitos de apoio discursivo (né?, tá?,), preenchedores de pausa (é..., ahn, uhn uhn, ahm ahn), especificadores (assim), iniciadores (Ah!) e finalizadores de turno (Então tá). Os resultados revelaram que: (i) os marcadores mais frequentes na fala das crianças são os sequenciadores ai e $e$; (ii) como Macedo (1997), os marcadores que apresentam funções mais complexas são adquiridos mais tardiamente.

Já com relação ao MD "então", vários estudos acerca de suas mudanças semântico-pragmáticas são reportados em português. Citem-se, por exemplo, os trabalhos de Martelotta (1994), Martelotta e Rodrigues (1996), Tavares (1999; 2003), Pezatti (2001), Oliveira e Arena (2010) e Chiarelli (2011), para citar alguns.

Martelotta (1994) procedeu a uma análise empírica de então em diversos contextos discursivos provenientes de entrevistas concedidas por crianças e adultos para os projetos Censo de Variação Linguística do Estado do Rio de Janeiro, Competências Básicas do Português ${ }^{8}$ e NURC/Rio de Janeiro (Norma Urbana Oral Culta). ${ }^{9} \mathrm{O}$ autor postula que os diferentes valores de então possuem uma origem espacial/temporal decorrentes de um processo de gramaticalização espaço > (tempo) > texto. A partir desse processo, o elemento tende a desempenhar funções pragmático-discursivas, ganhando novas posições mais fixas dentro da

\footnotetext{
${ }^{8}$ Hoje nomeado projeto PEUL (Programa de Estudos sobre o Uso da Língua), o Projeto Censo da Variação Linguística do Estado do Rio de Janeiro, visa ao estudo do português falado no Rio de Janeiro. O banco de dados do PEUL é composto por dois corpora: a amostra Censo 1980 e a amostra Censo 2000, ambas com gravação de falantes divididos por quatro faixas etárias (7-14 anos, 15-25 anos, 26-49 anos e mais de 50 anos).

${ }^{9} \mathrm{O}$ corpus da fala do Rio de Janeiro abrange um total de 394 entrevistas com 493 informantes.
} 
cláusula. O estudo revelou que o sentido espacial pode ser encontrado na origem latina do item intunc (in + tunc). Tunc (então), por sua vez, provém da união do elemento de intensificação tum (então, naquele tempo; depois disso; donde; além disso, por outro lado), que possui a mesma raiz dos pronomes demonstrativos latinos iste (esse), ista (essa), istud (isso) com a partícula ce, encontrável também na formação de pronomes demonstrativos latinos como hic(e) (este) e illic(e) (aquele). Essa origem demonstrativa de então (que remete a dados espaciais), presente no elemento tum e nos demais elementos de intensificação explica o valor anafórico, que este elemento apresenta até hoje. É desse valor anafórico que derivam os valores temporais e sequenciais. São sete os valores de então identificados pelo autor nas amostras: então anafórico, então sequencial, então introduzindo informação nova, então retomando assunto, então conclusivo, então alternativo e então intensificador.

A análise de Martelotta e Rodrigues (1996) com base no Corpus Discurso \& Gramática - a língua falada e escrita ${ }^{10}$ ratificou parcialmente a análise de Martelotta (1994), pois não foram localizados casos de então retomando assunto e apenas um uso não registrado identificado pelos autores como então resumitivo. As entrevistas analisadas apresentaram, portanto, sete diferentes valores de então.

Tavares $(1999,2003)$ investigou os sequenciadores retroativo-propulsores e, aí, dai ${ }^{11}$ então, responsáveis pelo estabelecimento de uma ponte entre um enunciado passado e um futuro, servindo o primeiro de base para o que será dito no segundo. Os dados de fala são provenientes de 48 entrevistas de Florianópolis pertencentes ao Banco de Dados do Núcleo Interinstitucional VARSUL (Variação Linguística Urbana na Região Sul do Brasil) $)^{12}$ estratificados em quatro faixas etárias: de 09 a 12 anos; de 15 a 21 anos; de 25 a 45 anos; acima de 50 anos. De modo geral, os resultados obtidos por meio de análise quantitativa apontam possibilidades de especialização de então sequenciador em contextos sociolinguísticos específicos.

O primeiro valor de então identificado na amostra de Tavares (2003) é o anafórico temporal, que, segundo a autora, origina o sequenciador temporal, resultando na transferência "tempo > conexão textual". O sequenciador temporal, por sua vez, deixa derivar o introdutor de efeito, o sequenciador textual e o retomador. $\mathrm{O}$ finalizador tem sua origem no introdutor de efeito. Outro uso conectivo do então, o alternativo, tal como em Martelotta (1994), introduz, juntamente com a conjunção $o u$, uma informação que representa uma opção em relação a uma informação dada anteriormente. Risso (1996, p. 430) citada por Tavares (2003) considera que o então alternativo traz implícita a mesma relação estabelecida pelo então conclusivo: "ou

${ }^{10}$ O Corpus Discurso \& Gramática - a língua falada e escrita visa a coleta, organização e armazenamento eletrônico de amostras de língua falada e escrita com informantes em cinco cidades brasileiras: Rio de Janeiro, Natal, Rio Grande, Juiz de Fora e Niterói.

${ }^{11}$ Conferir Tavares $(1999,2003)$ para detalhamento dos resultados de $e$, ai e daí.

${ }^{12} \mathrm{O}$ VARSUL foi implementado por quatro instituições do Sul do Brasil: UFRGS, UFSC, UFPR e PUCRS. Uma das metas do grupo de pesquisa é a descrição da variedade linguística urbana do português falado na Região Sul para comparação com resultados de outras regiões brasileiras. Para isso, conta com entrevistas gravadas de acordo com a metodologia sociolinguística, com informantes nativos de doze cidades, estratificados igualmente por etnia, idade, sexo e escolaridade, totalizando um acervo de 288 entrevistas. 
x, ou se não x, então y". Considerando-se essa hipótese, Tavares (1999) aponta a origem do então alternativo como sendo o então introdutor de efeito. Então interjectivo é usado como expressão denotativa de espanto ou admiração, podendo manifestar atenção ou assentimento do ouvinte ao falante. Como Martelotta (1994), o então intensificador ressalta uma informação acerca do elemento que possui por escopo, relativamente a outros elementos, com valor de mais ainda/ainda mais ou

principalmente. É possível que derive do sequenciador textual, devido ao traço que ambas as funções possuem em comum, qual seja, dar continuidade ao texto: além de o item que é intensificado ser aquele que, dentre outros possíveis, apresenta mais marcada alguma característica, representa mais um item introduzido em uma lista de itens, dando continuidade ao tópico tratado. O intensificador tem também traços do então finalizador: o item que modifica é o último de uma série de itens semelhantes. Finalmente, dos conectores sequenciadores surge, por discursivização, o então preenchedor de pausa. Salienta a autora que, embora não tenha encontrado dados referentes a então anafórico locativo, é possível que esse emprego, que já existiu na língua (cf. TAVARES, 1996), seja a fonte do uso anafórico temporal, valendo o percurso 'espaço > tempo' realizado pelo então.

Mesmo com a variedade de facetas funcionais através das quais se pode focalizar os conceitos e tipos de marcadores, um ponto comum que os une é seu caráter coesivo, anafórico, continuativo, sequencial.

\section{PROSÓdIA E MECANISMOS COESIVOS.}

Muito embora os mecanismos de sentido gerados a partir da correlação entre prosódia e texto tenham merecido boa atenção dos pesquisadores (ver, especificamente, CAGLIARI, 1992; OLIVEIRA JR, 2012, para o português brasileiro), pouco se tem estudado sobre a relação entre a prosódia e os marcadores discursivos. Exceção deve ser feita a trabalhos recentes que têm mostrado uma forte tendência ao comportamento específico de certos marcadores. Segundo Raso(2014), os marcadores discursivos têm caráter não-composicional sintático e semântico, isto é, não participam do conteúdo proposicional do enunciado. Compatível com essa natureza, são prosodicamente contidos numa única e exclusiva unidade tonal. Em outras palavras, são limitados por fronteiras prosódicas, separados do resto do enunciado por uma quebra ou fronteira perceptível de caráter não-terminal (isto é, de caráter continuativo), independentemente da posição que ocupam dentro do enunciado. Tais quebras ou fronteiras prosódicas antecedem ou seguem o marcador discursivo.

Com relação a mecanismos coesivos, a literatura mostra, a rigor, que o ouvinte não se baseia apenas nas marcas explícitas indexadas lexicalmente para fazer sentido de um texto oral. Do ponto de vista do papel da prosódia, há evidências de que os traços prosódicos e paralinguísticos (vocais e/ou gestuais) contribuem para a coesão e coerência de um texto oral, sobretudo em trechos de discurso relatado. $\mathrm{Na}$ verdade, Couper-Kuhlen (1998) ainda acrescenta que as pistas prosódicas e paralinguísticas são arregimentadas para fazer sentido da fala não só quando as marcas lexicais/ gramaticais estão pouco explícitas ou enganosas. 
Seriam as marcas prosódicas narrativas interpretáveis enquanto tais? Nos últimos anos, as pesquisas pendem para essa interpretação. Oliveira Jr., Cruz e Silva (2012) mostram que a estrutura de narrativas orais espontâneas é reconhecida através de suas pistas prosódicas, mesmo sem acesso a informações lexicais, sintáticas e semânticas.

Quais são as primeiras marcas prosódicas de coesão entonacional na fala da criança?

As primeiras tentativas de encadeamento prosódico de enunciados sucessivos de um vocábulo começam relativamente cedo na fala da criança e podem anteceder as construções sentenciais mais longas. Apontam para a força aglutinadora da entoação, que funciona como um envelope da relativa complexidade sintagmática de enunciados sucessivos de um vocábulo.

Segundo a teoria de Couper-Kuhlen (1993) sobre macroestruturas entoacionais, grupos ou unidades entoacionais combinam-se num nível superior para formar unidades maiores, que têm sido chamadas de sequências de tons, sequências de altura ou paratons. O termo paratom daria uma ideia mais da hierarquização numa unidade coesiva. A ideia central da prosódia do texto oral é que a entonação é responsável pela criação de gestalts fonológicos, isto é, o resultado é uma unidade de fala experienciada como um todo, internamente coesiva. Paratons (COUPER-KUHLEN, 1986) seriam a contraparte do parágrafo na ortografia; seriam responsáveis pela organização da estrutura do discurso, assim como os demais recursos léxico-gramaticais, da qual participa também o interlocutor (TENCH, 1996). Na verdade, pode-se dizer que a criança é exposta mais a paratons (ou, de modo mais específico, mas não necessariamente coincidente, a enunciados fonológicos, na concepção de NESPOR e VOGEL, 2007[1986]) do que a unidades menores ou frases entoacionais separadas (na concepção, por exemplo, de NESPOR e VOGEL, 2007[1986]), a partir de princípios prosódicos coesivos (SCARPA, 1985).

A emergência dos paratons interpretáveis como marcas de narratividade instauram-se, num primeiro momento, em rotinas dialógicas de contar estórias, relatos de experiência, descrições de pessoas e objetos apresentados pela mãe à criança.

\section{PROCEDIMENTOS METODOLÓGICOS.}

Neste trabalho, analisamos entoacionalmente dados de fala, que recobrem a faixa etária de 1;6 a 2;6, de uma criança, R. A análise entoacional consiste na transcrição e descrição dos eventos tonais associados aos trechos de fala nos quais aparecem o marcador discursivo "então". Nessa análise, buscamos as pistas prosódicas que revelam a migração de funcionalidade do marcador "então" de recurso coesivo e anafórico de ligação entre partes da narrativa para a função de "instaurador do jogo de contar estórias". Para tanto, assumimos a noção de paratons, conforme explicitada acima. Dada a migração de funcionalidade do marcador "então" de recurso coesivo que liga partes subsequentes da narrativa 
para "instaurador do jogo de contar estórias", esse marcador passa a se relacionar com o todo da narração e não apenas com as partes subsequentes da narrativa. Assim sendo, a caracterização prosódica do referido marcador não está vinculada apenas a uma unidade prosódica menor que contém o marcador e os trechos de fala imediatamente subsequentes a ele, mas a um agrupamento prosódico maior que engloba uma unidade discursiva.

A transcrição e descrição dos eventos tonais é feita com base na percepção auditiva, através do uso da ferramenta computacional Praat (BOERSMA; WEENINK, 2016) e levando em conta os pressupostos teóricos da Fonologia Entoacional (PIERREHUMBERT, 1980; BECKMAN; PIERREHUMBERT, 1986; LADD, 2008 [1996]).

De acordo com essa teoria de análise entoacional, os eventos tonais são compostos por níveis de tons primitivos ou por alvos da altura, alto $(\mathrm{H}-$ high $) \mathrm{e}$ baixo ( $\mathrm{L}$ - low), e podem ser de dois tipos: acentos tonais e tons relacionados a fronteiras.

Os acentos tonais são associados a sílabas proeminentes e podem ser simples (monotonais: $\mathrm{L}^{*}$ ou $\mathrm{H}^{*}$ ) ou complexos (bitonais: $\mathrm{H}^{*}+\mathrm{L}, \mathrm{H}+\mathrm{L}^{*}, \mathrm{~L}^{*}+\mathrm{H}$ ou $\mathrm{L}+\mathrm{H}^{*}$ ). Os tons relacionados a fronteiras são associados a fronteiras de constituintes prosódicos e correspondem aos tons de fronteira (boundary tones: $\mathrm{L} \%$ ou $\mathrm{H} \%$ ) e aos acentos frasais (phrasal accents: $\mathrm{L}^{-} \mathrm{ou} \mathrm{H}^{-}$).

A Figura 1 ilustra um exemplo de metodologia de análise empreendida neste trabalho.

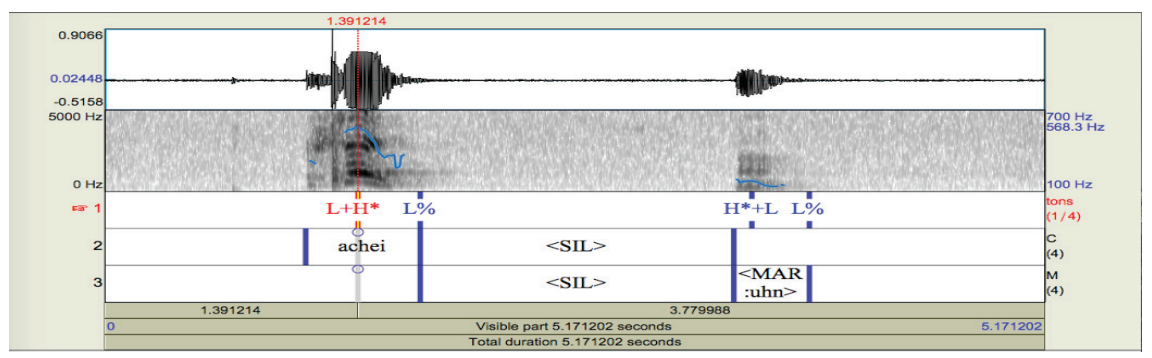

Figura 1: Segmentação e análise entoacional do trecho de fala "achei... uhn", sendo "achei" produzido pela criança (C) e "uhn" produzido pela mãe da criança (M).

$\mathrm{Na}$ parte superior da Figura 1, encontram-se, respectivamente, a forma de onda e o espectrograma mais a curva de $\mathrm{F}_{0}$ (linha azul), referentes ao sinal acústico do trecho de fala "achei... uhn". A primeira camada de anotação na figura, denominada "tons", destina-se à transcrição dos eventos tonais. Nas segunda e terceira camadas de anotação, são feitas, respectivamente, a segmentação da fala da criança (camada "C") e a segmentação da fala da mãe (camada "M"). A segmentação consiste na delimitação de fronteiras de palavras, pausas silenciosas (na figura, $<\mathrm{SIL}>$ ), fronteiras de marcadores discursivos não lexicais (na figura, $<$ MAR: uhn>) e outros elementos típicos da fala espontânea, como hesitações e interrupções, por exemplo. 
5. RESULTADOS.

Em nossos dados, o marcador discursivo então se revela como indicador de esquemas entoacionais narrativos, sendo realizado com configurações entoacionais $\left(\mathrm{L}^{*}+\mathrm{H} \mathrm{L} \% / \mathrm{H}^{*}+\mathrm{L} \mathrm{L} \%\right)$ que marcam foco ou ênfase em português brasileiro (FERNANDES, 2007; FROTA et al. 2015; entre outros). Na fala adulta, esse marcador exerce, entre outras, a função de partícula coesiva de um texto e encadeamento lógico ou temporal de eventos numa estória. Nas situações de relatar estórias ou fatos do cotidiano, geralmente demanda um marcador não lexical, indicador de atenção (em nossos dados, "ahn" ou "uhn"), como uma

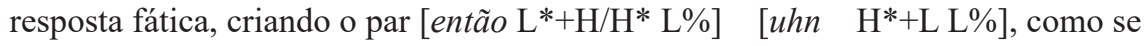
vê em (1) abaixo.

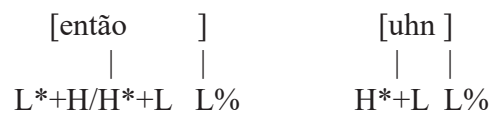

Há uma peculiaridade no uso deste vocábulo nos dados analisados: tanto na fala da mãe quanto na da criança, é também usado como artifício para instaurar um esquema de contar estórias. Neste sentido, migra da função de ligar diferentes blocos narrativos para a de instaurar uma fase inicial da estória. A configuração tonal caracterizadora de foco/ênfase $\left(\mathrm{L}^{*+\mathrm{H}} \mathrm{L} \% / \mathrm{H}^{*}+\mathrm{L} \mathrm{L} \%\right)$ em português brasileiro marca prosodicamente essa função de iniciar a estória em nossos dados.

A transcrição de dois episódios dialógicos abaixo ilustra a maneira pela qual o uso partilhado do par apresentado em (1) contribui para a construção de paratons narrativos na linguagem da criança.

(2) R. vê um livro de estórias e estende a mão para pegá-lo.

[então ]

L*+H L\%

[tão ]

|

$\mathbf{L} * \mathbf{H} \mathbf{L} \%$

[tão ]

| 1

$\mathbf{L}+\mathbf{H}^{*} \mathbf{L} \%{ }^{13}$

[tão ] (abrindo o livro)

|

$\mathrm{L}+\mathrm{H}^{*} \mathrm{~L} \%{ }^{14}$ imperativo.

${ }^{13}$ A criança emite este enunciado com uma configuração entoacional interpretada como

${ }^{14}$ Idem, interpretada como imperativo, só que insistente. 
[tão $]^{15}$ (pondo o livro no chão e começando a virar as páginas).

| 1

$\mathbf{H}^{*}+\mathbf{L} \mathrm{L} \%$

M. Então? Ah! (interpretando os enunciados anteriores de R. como requisição para contar estória à luz de um livro de gravuras).

\section{R. $[u h n]$}

$\mathbf{H}^{*}+\mathbf{L} \mathbf{L} \%$

M. Então...

R. $[u h n]$

$\mathbf{H}^{*}+\mathbf{L} \mathbf{L} \%$

M. ...o cachorrinho...

(...)

R. [então] (virando a página)

$$
\mathrm{L}+\mathrm{H} * \mathrm{~L} \%
$$

M. uhn.

R. [então] (virando a página)

$$
\mathrm{L}+\mathrm{H}^{*} \mathrm{~L} \%
$$

M. uhn.

R. desiste da brincadeira e entrega o livro à mãe.

$(1 ; 8)$

Deve ser notado que, em (2), a criança usa o marcador então para nomear o livro, a situação toda de contar estórias, para solicitar uma ação por parte da mãe, com os tons $\mathrm{L}^{*}+\mathrm{H} \mathrm{L} \% / \mathrm{L}+\mathrm{H}^{*} \mathrm{~L} \%$ (apontando para o livro e requisitando à mãe que participe do jogo e $\mathrm{H}^{*}+\mathrm{L}$ L\% (referindo-se à situação de "leitura"), respectivamente. $\mathrm{O}$ adulto, logo que consegue interpretar a intenção da criança, começa a contar uma pretensa estória ou representar o papel do narrador. A criança, então, finaliza sua estória com um tom descendente conclusivo ( $\mathrm{L}+\mathrm{H}^{*} \mathrm{~L} \%$ ), entregando o livro para a mãe e seu esquema narrativo (ou, entoacionalmente, seu paratom) tem um fecho.

Numa fase posterior, a criança faz uma tentativa mais sólida de assumir o papel de narrador. Veja em (3) abaixo.

(3) R. segura um livro com gravuras.

M. [que que tem aí? ]

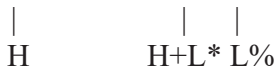

R. [(en)tão ]

$$
\mathrm{L}+\mathrm{H}^{*} \mathrm{~L} \%
$$

\footnotetext{
${ }^{15}$ Configuração entoacional interpretada como anuência.
} 


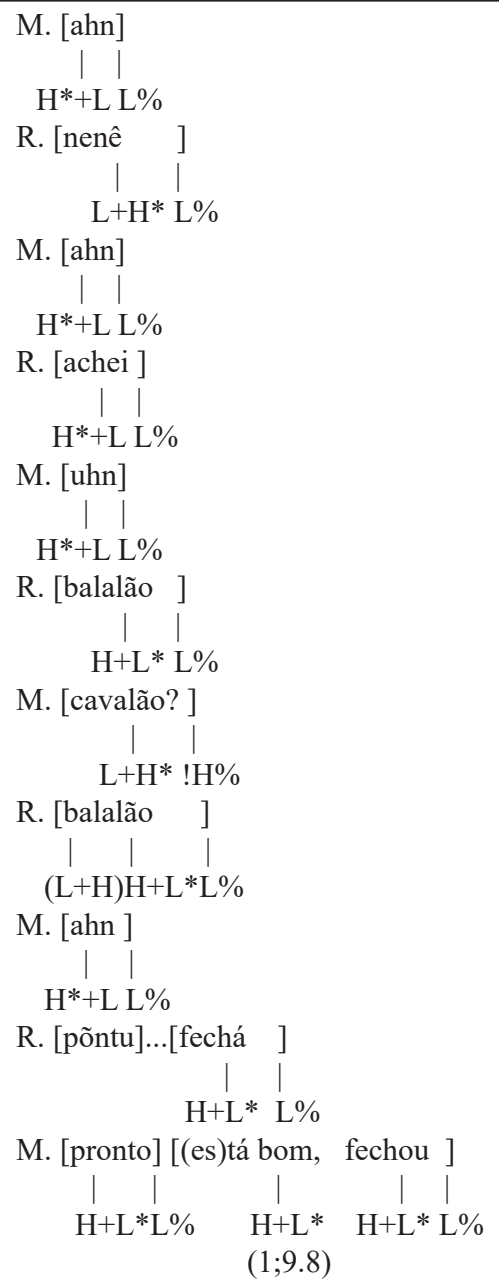

As figuras abaixo ilustram a análise entoacional apresentada no trecho de fala em (3).

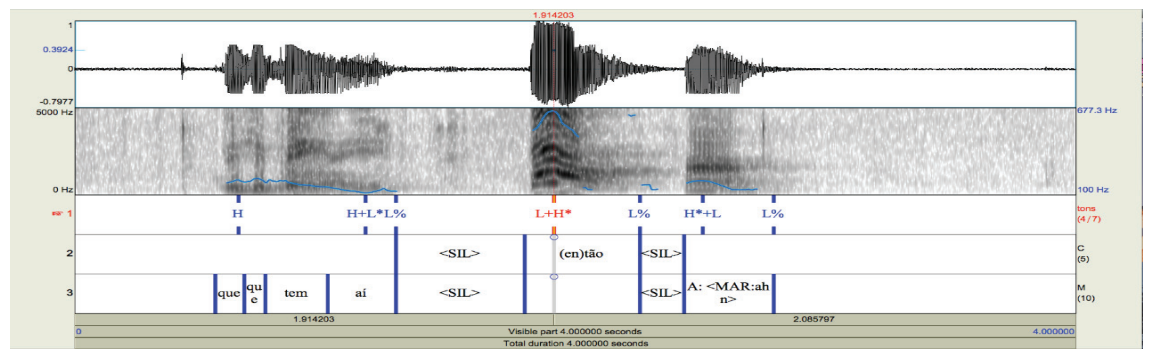

Figura 2: Segmentação e análise entoacional do trecho de fala

"Que que tem aí?...(en)tão...ahn”, sendo "(en)tão" produzido pela criança (C)

e "Que que tem aí?" e "ahn” produzidos pela mãe da criança (M). 


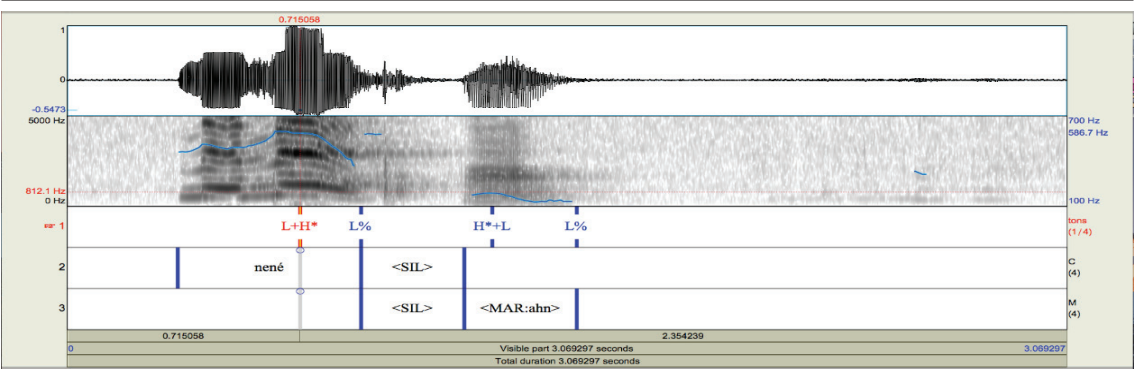

Figura 3: Segmentação e análise entoacional do trecho de fala "nené...ahn", sendo "nené" produzido pela criança (C) e "ahn" produzido pela mãe da criança (M).

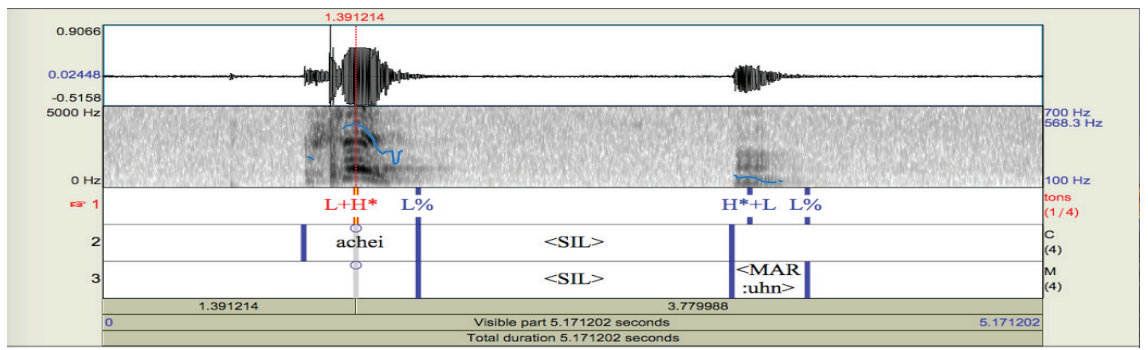

Figura 4: Segmentação e análise entoacional do trecho de fala "achei...uhn", sendo "achei" produzido pela criança $(C)$ e "uhn" produzido pela mãe da criança (M).

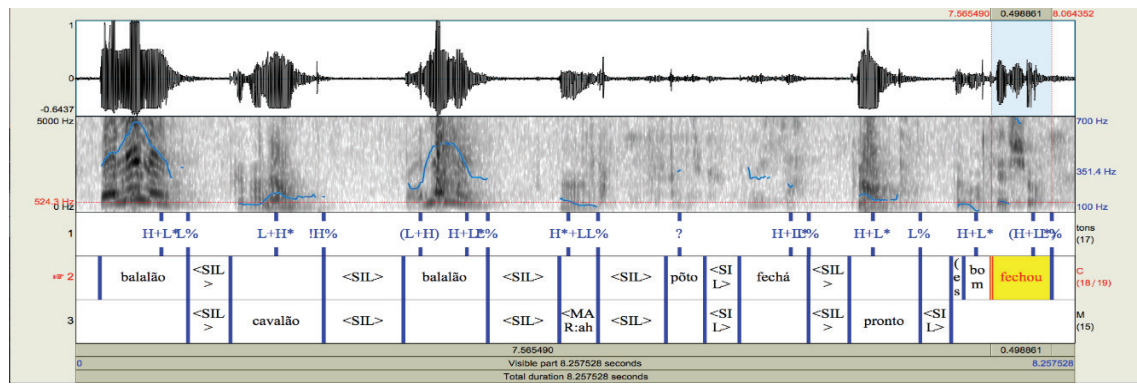

Figura 5: Segmentação do trecho da fala balalão...cavalão?...balalão...ahn...põto...fechá...pronto... (es)tá bom fechou", sendo "balalão", "balalão", "põto" e "fechá" produzidos pela criança (C) e "cavalão?", "ahn", "pronto" e "(es)tá bom fechou" produzidos pela mãe da criança (M).

Esta é a primeira tentativa registrada da criança de narrar alguma coisa mais substancial ao seu interlocutor: "então, nenê, achei, cavalo, pronto, fechar". A sequência de tons usada segue o mesmo esquema entoacional básico partilhado por ambos os interlocutores em jogos narrativos desse tipo: $\mathrm{L}+\mathrm{H} * \mathrm{~L} \%-\mathrm{L}+\mathrm{H} * \mathrm{~L} \%-$ $\mathrm{H} *+\mathrm{LL} \%-\mathrm{H}+\mathrm{L} * \mathrm{~L} \%-\mathrm{H}+\mathrm{L} * \mathrm{~L} \%$, isto é, uma série de tons enumerativos inconclusivos mais um descendente com terminal baixa, conclusivo, além de dois pontos terminais descendentes, encerrando a narrativa. A contribuição do interlocutor adulto é a constante inserção de um indicador de atenção nas lacunas deixadas pelas pausas entre os tons ascendentes incompletos. 
Seguindo ainda Scarpa (1985), entoacionalmente a fala narrativa desse sujeito expressa-se, neste caso, por sucessivos enunciados de um vocábulo. As diversas partes de um relato estão presentes, a saber, uma introdução $\left(\mathrm{L}^{*}+\mathrm{H} /\right.$ $\mathrm{L}+\mathrm{H}^{*} \mathrm{~L} \%$ então), instaurando o jogo de narrar; o desenrolar da estória, manifestado pela sequência de tons $\left[\mathrm{L}+\mathrm{H}^{*} \mathrm{~L} \%\right.$ ] atribuídos a vocábulos que nomeiam entidades presentes nas gravuras do livro; dois pontos terminais, um da própria estória, outro do turno, com dois tons descendentes de fechamento. Tal esquema entoacional, no entanto, não corresponde a uma narrativa propriamente dita. Não há, por exemplo, sucessão temporal de eventos interligados, nem há gramática interna da narrativa, mas referências esparsas a figuras conforme aparecem no livro e uma forma verbal, achei, que não tem relação semântica com os outros elementos, mas entra no mesmo paratom. Em outras palavras, não há narrativa stricto sensu, embora um esquema interacional ou um ritual narrativo esteja claro e a contribuição de ambos os participantes seja pragmaticamente significativa (através de uma ação partilhada) e linguisticamente manifesta (através do uso comum de um paratom).

Numa etapa posterior (faixa etária de 2;1 a 2;6), conforme a capacidade expressiva de R. se diversifica e fica mais complexa, exibindo maior desenvoltura em produzir enunciados longos e com um leque maior de episódios narrativos, os arcabouços prosódicos também se diversificam. As narrativas ficcionais, durante os meses que se seguem à construção dos primeiros paratons narrativos, começam a restringir-se a situações de "leituras" ou produções de estórias baseadas em livros ilustrados. A narrativa passa, assim, a ser intermeada por aspectos tangenciais do que se considera constitutivo de "gramáticas de texto": jogos de perguntas e respostas sobre características dos personagens sobre fatos- fictícios ou vividos - suscitados pelas gravuras, sobre circunstâncias de espaço; intervenções de colagens (cf. PERRONI, 1992), isto é, fragmentos de outros discursos, estórias ou mesmo objetos presentes no contexto imediato. O resultado é a produção de um texto não narrativo, ou pré-narrativo, no sentido de que não preenche ainda os critérios de identificação de um "discurso narrativo" previstos pela literatura. De fato, a literatura afirma que a criança toma parte em jogos de narrar bem antes de ser capaz de processar a intrincada estrutura de uma narrativa. Perroni (1992) mostra que, lá pelos três anos, a criança tem um molde linguístico de uma narrativa previamente conhecida, no qual ela pode inserir eventos experienciados, como uma colagem, ou combinar livremente diferentes ações ou atribuindo a eles (ações e eventos do presente) um status de realidade passada.

Entoacionalmente, dois procedimentos paralelos desenvolvem-se na fala de R, que se adaptam a essa nova situação:

1. O paratom inicial, que emerge num jogo típico de contar estórias, migra agora para situações de relatos pessoais. Passam a ser um modelo entoacional que imprime coesão a esse tipo de discurso. Veja, por exemplo, (4) e (5), registrados por volta de $2 ; 2$ a $2 ; 4$. 
(4) R. [fui icondê de você ]... [aqui no cubeitoi ]... [e massuquei lá ]... [e foi ]

$$
\mathrm{L}^{*+\mathrm{HL} \%} \quad \mathrm{~L}^{*+\mathrm{H} \mathrm{L} \%} \quad \mathrm{~L}^{*+\mathrm{H} \mathrm{L} \%} \quad \mathrm{H}^{*+\mathrm{L} \mathrm{L} \%}
$$

(Fui esconder de você, aqui no cobertor e machuquei lá e foi)

(5) Num passeio pelo campo, R. e outras crianças brincaram com uma perereca, fazendo-a saltar. À noite, R. relata o caso para M.

M. Raquel, o que é perereca?

R. [é ]...[um sapinho]

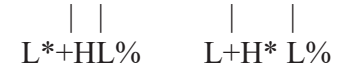

R. [então]...[o sapinho]...[pulou ]

$$
\text { L*+HL } \% \quad \text { L*+H } \quad \text { L\% } \quad \text { L+H*L\% }
$$

Observa-se que o paratom caracterizado pela sequência de configurações tonais $\mathbf{L} * \mathbf{H L} \%-\mathbf{L} *+\mathbf{H L} \%(-\mathbf{L} *+\mathbf{H L} \%)-\mathbf{L}+\mathbf{H} * \mathbf{L} \%$ é usado como modelo de tentativa de relatos pessoais - ou até mesmo de definições, porém adjacentes a relatos pessoais. O dado (5), acima, sustentado pela sucessão de tons encadeados, é a primeira tentativa bem sucedida de produção de um relato pessoal que segue critérios léxico-gramaticais e discursivos de uma narração: o tempo passado, a introdução, a resolução com um acontecimento inédito dentro do texto e o fecho narrativo.

Marcas ou fragmentos do paratom inicial, como tons inconclusos, o marcador então como marca introdutora de discurso narrativo e o fecho conclusivo descendente misturam-se a outros contornos no decorrer dos diálogos que conduzem a narrativas ficcionais. Os fragmentos de paratons narrativos são marcas de materialidade fônica que têm como efeito o reconhecimento de que um texto de cunho "narrativo" está sendo produzido pela criança. O diálogo abaixo é uma instanciação deste tipo de episódio, ocasião em que o sujeito fornece uma versão peculiar da estória da Branca de Neve, baseada num livro ilustrado. Note o uso de então como recurso introdutório da estória.

(6)

R. [então]

M. $\mathrm{Hm}$

R. [então ]

$$
\mathrm{L}^{*}+\mathrm{H} \mathrm{L} \%
$$

M. Ahn.

R. [A Banca de Neve ]

M. Hm.

R. [Pediu po pai dela ]

M. Hm.

$$
\begin{array}{c|}
\mid \\
\mathrm{L} *+\mathrm{H}
\end{array}
$$

R. eu quelo socolate.
M. Ahn.

R. socolate e pilulito.

M. Ah, é? E o pai dela deu?

R. Deu.

M. E depois?

R. Ele num deu.

M. Não deu? O que que o pai dela falou?

R. [O pai dela falou ]<smiles>[3H][Mg][13CH3]</smiles>

R. Ela fesa os olho/ [pa i duimi ]

$$
\text { L*+H L\% }
$$


6. CONCLUSÕES.

Há dois movimentos opostos na aquisição do marcador "então" na fala da criança pequena (entre 1;6 e 2;6) em instâncias interpretadas como narrativas.

Por um lado, comprova-se que as funções mais complexas dos marcadores discursivos não estão presentes na fala da criança numa faixa etária inicial do ponto de vista da produção linguística, como já notaram Macedo (1997) e Rost (2001).

Por outro lado, além do caráter coesivo e anafórico de ligação entre partes da narrativa, a dispersão e deslizamento funcionais de "então" atingem funções não presentes na fala adulta, como: migração de "então" para instaurar o jogo de contar estórias, requisição para esta instauração, nomeação do próprio jogo (processo de deslizamento metonímico). A migração de funcionalidade do marcador "então" de recurso coesivo sequenciador da fala adulta para, por exemplo, instaurador do jogo de contar estórias é identificada, na fala da criança, por marcas prosódicas caracterizadoras de ênfase/foco (configuração tonal $\mathrm{L}^{*}+\mathrm{H}$ L\%/ H*+L L\% - cf. FERNANDES, 2007; FROTA et al. 2015; entre outros). A configuração entoacional de ênfase/foco se justifica na caracterização dessa nova funcionalidade do marcador "então", uma vez que, ao se instaurar o jogo de contar estória, há, entre outros, o intuito de chamar a atenção do interlocutor e a estratégia utilizada para esse fim pode se dar através da marcação prosódica de ênfase/foco.

Não se verifica uma gramática narrativa propriamente dita, mas o efeito de narratividade provém de arranjos prosódicos e do uso peculiar do marcador "então". Como vimos, não há estrutura interna indexada léxico-gramatical, nem textualmente (fazendo uso dos mecanismos coesivos da língua) de uma narrativa stricto sensu. Não há, no começo, sucessão interconectada de eventos nem a resolução interna com o acontecimento singular e inédito, digno de ser narrado (LABOV, 1972). Por outro lado, o texto resultante é reconhecido como sendo de natureza narrativa. O marcador "então", delimitado como uma unidade prosódica (isto é, delimitado por tons de fronteira, notados como \%), conforme apontara Raso (2014), desencadeia o texto, constituído por nomeações de figura e colagens de fragmentos discursivos. A unidade do texto é dada pela interação entre a configuração prosódica de tons e a seleção de um marcador específico, na fala do nosso sujeito.

Reafirmamos que a prosódia tem se mostrado uma entrada ótima para a aquisição da linguagem. Tem sido largamente aceito que as interfaces entre a prosódia e outros componentes fornecem a ponte entre os aspectos mais formais, através dos sistemas de ritmo e entoação das línguas (SCARPA, 1999) e os mais discursivos e dialógicos da atividade linguística (SCARPA, 1990). A ação combinada entre a prosódia e a organização do texto (que, na fala adulta, foi bem observada por OLIVEIRA JR., 2000) parece estar presente desde muito cedo na fala da criança. 


\section{REFERÊNCIAS}

BECKMAN, M.; PIERREHUMBERT, J. Intonational structure in Japanese and English. Phonology Yearbook, n. 3, pp. 255-310, 1986.

BOERSMA, P; WEENINK, D. PRAAT: doing phonetics by computer [Computer program]. Versão 6.0.20. Disponível em: <http://www.praat.org/>. Acesso em: 3 set. 2016.

CAGLIARI, L. C. Prosódia: algumas funções dos supra segmentos. Cadernos de Estudos Linguísticos, n. 23, pp. 137-151, 1992.

CASTILHO, A. T. Para o estudo das unidades discursivas no português falado. In: Português culto falado no Brasil. Campinas: Editora da UNICAMP, 1989. pp. $249-279$. (Org.).

CHIARELLI, G. A. A gramaticalização de então no português paulista: um estudo pancrônico. Dissertação (Mestrado em Estudos Linguísticos) - Universidade Estadual Paulista, Instituto de Biociências, Letras e Ciências Exatas, 2011. Disponível em: <http://hdl.handle.net/11449/86552>.

COUPER-KUHLEN, E. An Introduction to English Prosody . London and Tübingen: Edward Arnold and Niemeyer, 1986.

COUPER-KUHLEN, E. Coherent Voicing. On Prosody in Conversational Reported Speech, InLiSt $\mathrm{N}^{\circ} 1$, Interaction and Linguistic Structures, 1998, pp. 1-26.

FERNANDES, F. R. Ordem, focalização e preenchimento em português: sintaxe e prosódia. 2007. Tese (Doutorado em Linguística) - Universidade Estadual de Campinas, Campinas, 2007.

FRASER, B. What are discourse markers? Journal of Pragmatics, v. 31, 1999, pp. 931-952.

FROTA, S.; CRUZ, M.; FERNANDES-SVARTMAN, F.; COLLISCHONN, G.; FONSECA, A.; SERRA, C.; OLIVEIRA, P.; VIGÁRIO, M. Intonational variation in Portuguese: European and Brazilian varieties. In: FROTA, S; PRIETO, P. (Eds.). Intonational variation in Romance. Oxford: Oxford University Press, 2015.

KOMAR. S. The interface between intonation and function of discourse markers in English. In: KOMAR, S.; MOZETIC, U. Studies in the English Language and Literature in Slovenia, vol. IV/ 1-2. Liubliana, 2007.

LABOV, W. Language in the Inner City: Studies in Black English Vernacular. Filadélfia, University of Pennsylvania Press, 1972.

LABOV, W.; FANSHEL, D. Therapeutic Discourse: Psychotherapy as Conversation. New York, Academic Press, 1977.

LADD, D. R. Intonational Phonology. Cambridge: Cambridge University Press, 1996.

MACEDO, A. V. T. Aquisição de marcadores em primeira e segunda língua. In: RONCARATI, C; MOLLICA, M. C. (Orgs.). Variação e aquisição. Rio de Janeiro: Tempo Brasileiro, 1997.

MARCUSCHI, L. A. Marcadores conversacionais do português brasileiro: formas, funções e definições. In: CASTILHO, A. (Org.). Português culto falado no Brasil. Campinas: Ed. da UNICAMP, 1989.

MARTELOTTA, Mário Eduardo T. 1994. Os circunstanciadores temporais e sua ordenação: uma visão funcional. Tese (Doutorado em Linguística) - Universidade Federal do Rio de Janeiro, Rio de Janeiro: UFRJ,1994. 
MARTELOTTA, M. E.; RODRIGUES, L. Gramaticalização de Então. In: MARTELOTTA, M. E; VOTRE, S. J; CESÁRIO, M. (Orgs.). Gramaticalização no Português do Brasil: Uma Abordagem Funcional. Rio de Janeiro: Tempo Brasileiro, 1996, pp. 221-236.

NESPOR, M.; VOGEL, I. Prosodic Phonology. Dordrecht: Foris Publications, 1986.

OLIVEIRA, M. R.; ARENA, A. B. Padrões funcionais do elemento então em sequências tipológicas do português: uma abordagem pancrônica. Revista Veredas, v. 1, pp. 36-52, 2010.

OLIVEIRA JR. M. Prosodic Features in Spontaneous Narratives. Tese de Doutorado, Simon Fraser University, Vancouver, 2000.

OLIVEIRA JR., M.; CRUZ, R.; SILVA, E. A relação entre a prosódia e a estrutura de narrativas espontâneas: um estudo perceptual. Revista Diadorim, v. 12, 2012, 38-53.

PEZATTI, Erotide Goreti2001PEZATTI, E. G. O advérbio 'então' já se gramaticalizou como conjunção? DELTA. Documentação de Estudos em Linguística Teórica e Aplicada, São Paulo, v. 17, n.1, pp. 81-95, 2001.

PERRONI, M. C. O desenvolvimento do discurso narrativo. São Paulo: Martins Fontes, 1992.

PIERREHUMBERT, J. The phonology and phonetics of English intonation. 1980. Tese (Doutorado) - Massachusetts Institute of Technology, Cambridge, Mass., 1980.

RASO, T. Prosodic constraints for discourse markers. In: RASO, T; MELLO, H. (Orgs.). Spoken corpora and linguistic studies. Amsterdam, John Benjamins Publishing Company, pp. 411-467, 2014.

RISSO, M. S. 'Agora... o que eu acho é o seguinte': um aspecto da articulação do discurso no português culto falado. In: CASTILHO, A.T. de. Gramática do Português Falado, Vol. III: As abordagens. Campinas: Editora da UNICAMP/FAPESP, 1993, pp. 31-60.

RISSO, M. S. O articulador então. In: CASTILHO, A. T.; BASÍLIO, Margarida (Org.). Gramática do Português Falado, Vol. IV: Estudos Descritivos. Campinas: Editora da UNICAMP/FAPESP, 1996, pp. 423-452.

RISSO, M. S. Aspectos textuais-interativos dos marcadores discursivos de abertura Bom, Bem, Olha, Ah, no português culto falado. In: NEVES, Maria Helena de Moura. Gramática do português falado. Vol. VII Campinas: Ed. da UNICAMP/FAPESP, 1999, pp. 259-296.

RISSO, M. S.; SILVA, G. M.; URBANO, H. Marcadores discursivos basicamente sequenciadores. In: JUBRAN, C. A. S; KOCH, I. V. (Org.). Gramática do português culto falado no Brasil. Campinas: Editora da UNICAMP, Vol. 1 (Construção do texto falado), pp. 427-496, 2006.

ROJO, R. H. R. A emergência da "coesão" narrativa: "E daí" em narrativas infantis. Revista Delta, São Paulo, v. 12, n. 1, pp. 57-86, 1996.

ROST-SNICHELOTTO, C. A. Olha e vê: caminhos que se entrecruzam. Tese (Doutorado em Linguística). Programa de Pós-graduação em Linguística, Universidade Federal de Santa Catarina, Florianópolis, 2009.

ROST, C. A. Olha e veja: multifuncionalidade e variação. Dissertação (Mestrado em Linguística). Programa de Pós-graduação em Linguística, Universidade Federal de Santa Catarina, Florianópolis, 2002.

ROST, C. A. A aquisição de marcadores discursivos: uma trilha. Florianópolis: UFSC, 2001. [Mimeo] 
SCARPA, E. M. A emergência da coesão intonacional. Cadernos de Estudos Linguísticos, v. 8, pp. 31-41, 1985.

SCARPA, E. M. Intonation and Dialogue Processes in Early Speech. In: CONTI-RAMSDEN; SNOW, C (Orgs.). Child Language, v. 7. Hillsdale, EUA: Lawrence Erlbaum, pp. 147-170, 1990.

SCARPA, E. M. Interfaces entre componentes e representação na aquisição da prosódia. In LAMPRECHT, R. R. (Org.). Aquisição da Linguagem. Questões e Análises. Porto Alegre: Editora da PUCRS, pp. 65-80, 1999

SCHIFFRIN, D. Discourse markers. Cambridge: Cambridge University Press, 1987.

SCHIFFRIN, D. Discourse markers: language, meaning and context. In: ; TANNEN, Deborah; HAMILTON, H. E. (Eds.). The Handbook of Discourse Analysis. Malden, MA: Blackwell, pp. 54-74, 2003.

SILVA, G. M.; MACEDO, A. Análise sociolinguística de alguns marcadores conversacionais. In: MACEDO, A; RONCARATI, C; MOLliCA, M. C.(Org.). Revista Tempo Brasileiro, pp. 11-49, 1989.

TAVARES, M. A. A gramaticalização de $e$, aí, então: estratificação/variação e mudança no domínio funcional da sequenciação retroativo-propulsora de informações - um estudo sociofuncionalista. Tese (Doutorado em Linguística) - Universidade Federal de Santa Catarina, Programa de PósGraduação em Linguística, Florianópolis, 2003.

TAVARES, M. A. Um estudo variacionista de aí, daí, então, e como conectores sequenciadores retroativo-propulsores. Dissertação (Mestrado em Linguística), Universidade Federal de Santa Catarina, Florianópolis, 1999.

TAVARES, M. A. Então no túnel do tempo: um estudo das funções do então nos séculos XIV, XVI e XVIII. Florianópolis: Universidade Federal de Santa Catarina, 1996. [Mimeo]

TENCH, P. The intonation systems of English. London: Cassell, 1996.

VOTRE, S. J; MARTELOTTA, M. E.; CEZARIO, M. C. Gramaticalização. Rio de Janeiro: Editora da UFRJ, 2004. 